Check for updates

Cite this: RSC Adv., 2018, 8, 19827

\title{
Near infrared light activatable PEI-wrapped bismuth selenide nanocomposites for photothermal/photodynamic therapy induced bacterial inactivation and dye degradation $\uparrow$
}

\author{
Govinda Gorle, (D) Ayyappa Bathinapatla, Yi-Zhan Chen and Yong-Chien Ling (DD *
}

\begin{abstract}
The inactivation of bacteria and the degradation of organic pollutants by engineered nanomaterials (NMs) are very effective approaches for producing safe and clean drinking water. The development of new NMs which can act as NIR light mediated antimicrobial agents as well as photocatalytic agents is highly desired. In this study, a novel $\mathrm{Bi}_{2} \mathrm{Se}_{3}$ nanoplates (NPs) NM was prepared by a high-temperature reaction (colloidal synthesis) followed by wrapping of the surface with polyethyleneimine (PEI) through electrostatic interactions. The developed $\mathrm{Bi}_{2} \mathrm{Se}_{3}$ NPs/PEI exhibited excellent NIR light activated antimicrobial properties for bacterial eradication and efficient photocatalytic properties for organic dye degradation. The results showed that upon $808 \mathrm{~nm}$ laser irradiation the engineered $\mathrm{Bi}_{2} \mathrm{Se}_{3} \mathrm{NPs} / \mathrm{PEI}$ eradicated $\sim 99 \%$ of $S$. aureus and $\sim 97 \%$ of $E$. coli bacteria within 10 minutes of irradiation through combined dual-modal photothermal therapy (PTT) and photodynamic therapy (PDT) via the generation of heat and reactive oxygen species, respectively. The contributions of PTT and PDT were found to be in a ratio of nearly $4: 1$ in the killing of both species of bacteria. In addition, $\mathrm{Bi}_{2} \mathrm{Se}_{3} \mathrm{NPs} / \mathrm{PEl}$ also acted as an excellent photocatalyst under illumination by a halogen lamp equipped with a 700-1100 nm band pass filter to achieve degradation efficiencies of $\sim 95 \%$ for methylene blue and $\sim 93 \%$ for Rhodamine B within 3 and $4 \mathrm{~h}$, respectively. To the best of our knowledge, this is the first demonstration of these NIR light activated antimicrobial properties, photodynamic properties and photocatalytic properties mediated by $\mathrm{Bi}_{2} \mathrm{Se}_{3} \mathrm{NPs}$.
\end{abstract}

Received 12th March 2018

Accepted 1st May 2018

DOI: 10.1039/c8ra02183j

rsc.li/rsc-advances

\section{Introduction}

There are growing concerns about drinking water safety, requiring the removal of contaminants such as toxic pathogenic microorganisms like Staphylococcus aureus (S. aureus) and Escherichia coli $\left(E\right.$. coli) as well as organic pollutants. ${ }^{1}$ The conventional method for treating bacterial infections is the usage of antibiotics. ${ }^{2}$ However, the overusage of antibiotics inevitably leads to the development of antibiotic-resistant bacterial strains, which potentially becomes a serious threat to public health. ${ }^{3}$ Therefore, it is necessary to develop novel antibacterial materials and/or new approaches for the effective killing of pathogenic bacteria. In recent times, phototherapy, including photothermal therapy (PTT) ${ }^{4,5}$ and photodynamic therapy $(\mathrm{PDT})^{6}$ has attracted great attention as a capable antimicrobial technique due to its high therapeutic efficiency and minimal side effects.

Department of Chemistry, National Tsing Hua University, Hsinchu 30013, Taiwan. E-mail: ycling@mx.nthu.edu.tw

$\dagger$ Electronic supplementary information (ESI) available. See DOI: $10.1039 / \mathrm{c} 8 \mathrm{ra} 02183 \mathrm{j}$
In PTT, photoabsorbing agents are delivered to the target bacteria, and are then irradiated with a near infrared (NIR, 700$1100 \mathrm{~nm}$ ) light and the absorbed optical energy is converted into heat energy to cause cell damage and subsequent bacterial eradication. ${ }^{7}$ Various photothermal agents (PTA) such as gold nanomaterials (NMs), ${ }^{8,9}$ graphene based NMs, ${ }^{10,11}$ and organic nanoparticles ${ }^{12}$ have been explored for efficient photothermal bacterial eradication. Nevertheless, it is highly desirable to develop and engineer new PTAs that can effectively target and destroy bacteria.

Alternatively, PDT is an approach which involves the use of photosensitizers (PSs), light, and molecular oxygen $\left({ }^{3} \mathrm{O}_{2}\right)$ to induce the formation of singlet oxygen $\left({ }^{1} \mathrm{O}_{2}\right)$ and other reactive oxygen species (ROS), which are able to kill pathogenic bacteria. ${ }^{13}$ In this method, organic dyes, for example phthalocyanines, porphyrins, and chlorins etc., have been used as PSs. However, the adverse effects of these dyes, such as skin infections and oral disinfection, limit their clinical applicability. ${ }^{14}$ In addition, most of these PSs are typically activated by using UV/ visible light, which has limited tissue penetration depths. Recently, a few studies have focused on the design of new PSs that can generate ROS and destroy bacteria upon NIR light 
irradiation..$^{\mathbf{1 3 1 5 - 1 7}}$ There is an urgent need to develop and engineer new PSs that can effectively target and destroy bacteria.

Of late, dual-modal phototherapeutics have been developed that combine PTT and PDT and exhibit synergistically enhanced therapeutic efficacy compared to PTT or PDT alone in cancer treatment. ${ }^{18}$ However, the exploration of dual-mode phototherapeutics in bacterial eradication is still in its infancy stage. ${ }^{\mathbf{1 9}}$ Therefore, the development of dual-modal antimicrobial agents with bacteria targeting ability to simultaneously deliver both PTT and PDT under single laser irradiation for bacterial eradication is highly significant.

Similar to bacteria, organic pollutants in waste water also adversely affect human health. ${ }^{20}$ Currently, NM based photocatalytic technology for the degradation of organic pollutants has been regarded as one of the most promising routes for the decontamination of waste water. ${ }^{21}$ This photocatalytic technology is a process in which photoenergy converts into chemical energy and generates ROS for dye degradation. ${ }^{22}$ Until now, various NMs have been investigated for photocatalytic activity, including $\mathrm{Bi}_{2} \mathrm{WO}_{6} / \mathrm{BiVO}_{4},{ }^{22} \mathrm{Bi}_{2} \mathrm{O}_{3},{ }^{21}$ poly(methyl methacrylate)/ $\mathrm{TiO}_{2},{ }^{23} \mathrm{Ag}$ nanoparticles/BiVO $4,{ }^{24}$ and CNT/AgI. ${ }^{25}$ However, most of these photocatalysts require UV light/visible light to be activated. Therefore the development of photocatalytic agents that can be activated by NIR light which has high occupation of the solar spectrum is more desirable. ${ }^{26}$ Previously, up-conversion nanoparticles have been reported for NIR light mediated photocatalytic activity; however it took a long time for dye degradation to occur. ${ }^{27}$ Therefore, there is much need to develop new NIR mediated photocatalytic agents with lower degradation times and good water solubilities.

In recent times, among various transition metal chalcogenides bismuth selenide $\left(\mathrm{Bi}_{2} \mathrm{Se}_{3}\right) \mathrm{NMs}^{28,29}$ have been explored in biomedical applications such as bioimaging, ${ }^{30}$ radiation therapy, ${ }^{31}$ and PTT $^{32}$ of cancer. However, the photothermal bacterial killing ability of $\mathrm{Bi}_{2} \mathrm{Se}_{3} \mathrm{NMs}$ has not been explored yet. In addition, the NIR light mediated photodynamic properties and photocatalytic properties of $\mathrm{Bi}_{2} \mathrm{Se}_{3}$ NMs have not been explored to date.

It is well known that bacterial cells are negatively charged due to the high proportion of anionic phospholipids in their cell walls; this leads to the strong affinity between bacteria and positively charged surfaces through electrostatic interaction. Previously, it has been reported that materials of which the surfaces were engineered with cationic polyethyleneimine (PEI) exhibited a bacteria targeting ability towards both Gram negative (E. coli) and Gram positive bacteria ( $S$. aureus) through electrostatic interaction and enhanced antibacterial efficacy. ${ }^{33}$ In addition, surface engineering with PEI provides good dispersion of materials in polar solvents such as water and buffers. ${ }^{34-36}$

Herein, we report the synthesis and application of PEIwrapped $\mathrm{Bi}_{2} \mathrm{Se}_{3}$ nanoplates $\left(\mathrm{Bi}_{2} \mathrm{Se}_{3} \mathrm{NPs} / \mathrm{PEI}\right)$ as a novel bacteria targeting dual-modal phototherapeutic agent for combined PTT and PDT mediated bacterial eradication as well as a novel NIR mediated photocatalytic agent (Scheme 1). In this study, the engineering of $\mathrm{Bi}_{2} \mathrm{Se}_{3}$ NPs with PEI conferred the NPs with bacteria targeting ability through electrostatic interaction

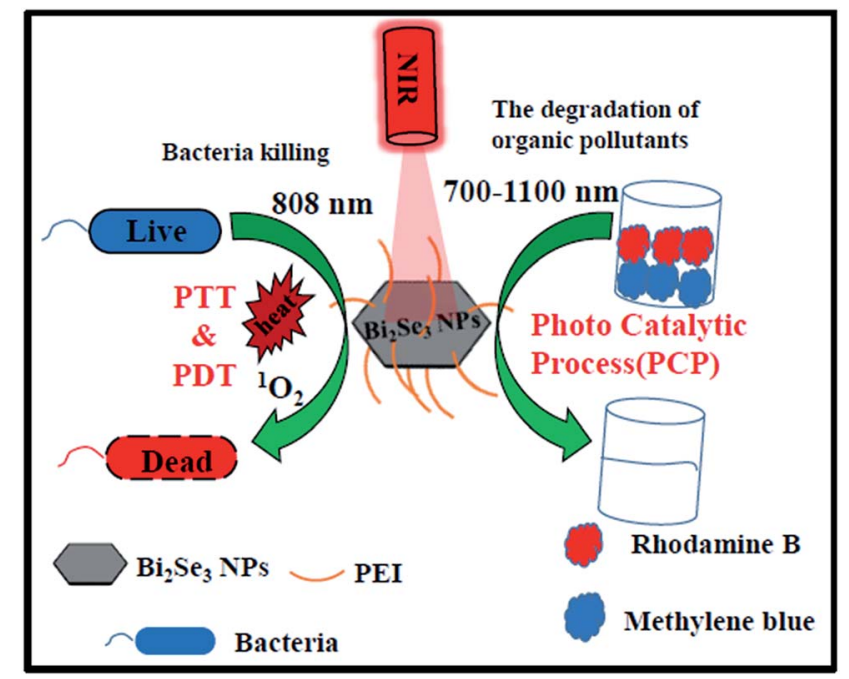

Scheme 1 Schematic for NIR light mediated antibacterial and photocatalytic activity of $\mathrm{Bi}_{2} \mathrm{Se}_{3} \mathrm{NPs} / \mathrm{PEI}$.

along with good water dispersion. This $\mathrm{Bi}_{2} \mathrm{Se}_{3}$ NPs/PEI material exhibited high antibacterial efficacy through combined PTT and PDT upon a single irradiation with an $808 \mathrm{~nm}$ laser. In addition, the developed $\mathrm{Bi}_{2} \mathrm{Se}_{3}$ NPs/PEI also demonstrated excellent NIR light mediated photocatalytic activity for degradation of methylene blue (MB) and rhodamine $\mathrm{B}(\mathrm{RhB})$. To the best of our knowledge, this is the first report exploring the NIR light mediated antimicrobial properties, photodynamic properties and photocatalytic activity of $\mathrm{Bi}_{2} \mathrm{Se}_{3}$ NPs.

\section{Experimental section}

\section{Synthesis}

$\mathrm{Bi}_{2} \mathrm{Se}_{3}$ NPs were prepared according to the previously reported method with slight modifications. ${ }^{37}$ Briefly, appropriate amounts of $\mathrm{Bi}\left(\mathrm{NO}_{3}\right)_{3}(1 \mathrm{mM})$ and $\mathrm{Na}_{2} \mathrm{SeO}_{3}(1.5 \mathrm{mM})$ were mixed and dissolved in ethylene glycol $(35 \mathrm{~mL})$ with vigorous stirring for $1 \mathrm{~h}$. The mixed solution was subsequently refluxed at $260{ }^{\circ} \mathrm{C}$ for $5 \mathrm{~h}$. Finally, the reaction mixture was cooled to room temperature and isopropyl alcohol was added to precipitate the $\mathrm{Bi}_{2} \mathrm{Se}_{3}$ NPs. The precipitate was washed with acetone and DI water several times, to remove any unreacted chemicals as well as ethylene glycol, and was further dried in an oven for $6 \mathrm{~h}$ at $50{ }^{\circ} \mathrm{C}$. To prepare the aqueous solution containing dispersed $\mathrm{Bi}_{2} \mathrm{Se}_{3} \mathrm{NPs} / \mathrm{PEI}$, as-prepared $\mathrm{Bi}_{2} \mathrm{Se}_{3}$ NPs (50 mg) was dissolved in DI water $(50 \mathrm{~mL})$ by sonication for $10 \mathrm{~min}$. PEI $(20 \mu \mathrm{L})$ was slowly added. The solution was subjected to continuous stirring for $24 \mathrm{~h}$ at room temperature. The obtained $\mathrm{Bi}_{2} \mathrm{Se}_{3} \mathrm{NPs} / \mathrm{PEI}$ was washed several times with DI water to remove unbound PEI.

\section{NIR light mediated photothermal effect}

Different concentrations (10, 30, 50, and $80 \mathrm{ppm})$ of $\mathrm{Bi}_{2} \mathrm{Se}_{3} \mathrm{NPs} /$ PEI and $\mathrm{Bi}_{2} \mathrm{Se}_{3}$ NPs (80 ppm) were dispersed in PBS solution followed by irradiation with an $808 \mathrm{~nm}$ laser at $1 \mathrm{~W} \mathrm{~cm}^{-2}$ for $10 \mathrm{~min}$. To investigate the effect of power density, $\mathrm{a} \mathrm{Bi}_{2} \mathrm{Se}_{3} \mathrm{NPs} /$ 
PEI solution $(80 \mathrm{ppm})$ was irradiated at different laser power densities $\left(0.5,1\right.$, and $\left.1.5 \mathrm{~W} \mathrm{~cm}^{-2}\right)$. The solution temperature was recorded every 2 min using a thermocouple to monitor the temperature change. The calculation of photothermal conversion efficiency was detailed in the ESI. $\dagger$

\section{NIR light mediated singlet oxygen generation}

The generation of ${ }^{1} \mathrm{O}_{2}$ in the presence of $\mathrm{Bi}_{2} \mathrm{Se}_{3} \mathrm{NPs}$ or $\mathrm{Bi}_{2} \mathrm{Se}_{3}$ NPs/PEI upon laser irradiation was measured by recording the absorbance change of DPBF.$^{18}$ In a typical experiment, appropriate amounts of $\mathrm{Bi}_{2} \mathrm{Se}_{3}$ NPs or $\mathrm{Bi}_{2} \mathrm{Se}_{3}$ NPs/PEI $\left(1 \mathrm{mg} \mathrm{mL}{ }^{-1}\right)$ and DPBF $(0.08 \mathrm{mM})$ were mixed in ethanol $(2 \mathrm{~mL})$ contained in a quartz cuvette followed by irradiation with an $808 \mathrm{~nm}$ laser at $1 \mathrm{~W} \mathrm{~cm}^{-2}$. The DPBF $\left(\lambda_{\mathrm{abs}}=410 \mathrm{~nm}\right)$ readily reacted with ${ }^{1} \mathrm{O}_{2}$ and formed a bleached adduct which caused a decrease in absorbance. The change in absorbance of the solution at $410 \mathrm{~nm}$ upon laser irradiation was recorded every 2 min over a period of 12 min using a UV-vis spectrophotometer.

The generation of ${ }^{1} \mathrm{O}_{2}$ in the bacterial solution (both E. coli and $S$. aureus) was tested using DCFH-DA and a confocal fluorescence assay. In this experiment, DCFH-DA $(10 \mu \mathrm{L})$ was added to a bacterial solution containing $\mathrm{Bi}_{2} \mathrm{Se}_{3} \mathrm{NPs} / \mathrm{PEI}$ (80 $\mathrm{ppm}$ ). The solution was irradiated with an $808 \mathrm{~nm}$ laser for $10 \mathrm{~min}$ and visualized under a CLSM confocal microscope (Zeiss, LSM 700). A blue colour indicated the presence of bacteria and a green colour indicated the generation of ${ }^{1} \mathrm{O}_{2}$ in the bacteria solution.

\section{NIR light mediated antibacterial activity}

The antibacterial activity of the as-prepared $\mathrm{Bi}_{2} \mathrm{Se}_{3} \mathrm{NPs}$ and $\mathrm{Bi}_{2} \mathrm{Se}_{3} \mathrm{NPs} / \mathrm{PEI}$ was evaluated using Gram-positive $S$. aureus (BCRC 11863) and Gram-negative E. coli (BCRC 11509) as test organisms. All glassware and required equipment was sterilized in an autoclave at $120^{\circ} \mathrm{C}$ before microbiological experiments. $S$. aureus and $E$. coli cultures were grown on nutrient agar for $24 \mathrm{~h}$, then transferred into an Erlenmeyer flask containing nutrient broth (Scharlau Chemie, Spain) at an initial optical density at $600 \mathrm{~nm}$ (OD 600) of 0.1 , and allowed to grow at $37^{\circ} \mathrm{C}$ for $16 \mathrm{~h}$. The bacteria were spun down by centrifugation and the resultant pellet was washed twice with a saline solution $(0.9 \%)$ to yield a final bacterial concentration of $\sim 10^{6}$ to $10^{7} \mathrm{CFU} \mathrm{mL}^{-1}$. Different concentrations of $\mathrm{Bi}_{2} \mathrm{Se}_{3} \mathrm{NPs} / \mathrm{PEI}(10,30,50$, and 80 ppm) were incubated at $37^{\circ} \mathrm{C}$ with bacterial solution $(1 \mathrm{~mL})$ in separate vials for $30 \mathrm{~min}$. The bacteria along with the captured $\mathrm{Bi}_{2} \mathrm{Se}_{3}$ NPs (80 ppm) or $\mathrm{Bi}_{2} \mathrm{Se}_{3}$ NPs/PEI were spun down by centrifugation and the supernatant containing free $\mathrm{Bi}_{2} \mathrm{Se}_{3} \mathrm{NPs} /$ PEI was discarded. The bacteria- $\mathrm{Bi}_{2} \mathrm{Se}_{3} \mathrm{NPs}$ or $-\mathrm{Bi}_{2} \mathrm{Se}_{3} \mathrm{NPs} / \mathrm{PEI}$ pellet was dispersed in PBS and irradiated with an $808 \mathrm{~nm}$ laser light $\left(1 \mathrm{~W} \mathrm{~cm}^{-2}\right)$ for $10 \mathrm{~min}$. The distance was maintained at $7 \mathrm{~cm}$ between the bacterial solution and the laser source. An appropriate aliquot of the suspension $(100 \mu \mathrm{L})$ was collected, and diluted about 50 times. An appropriate amount of the diluted solution $(100 \mu \mathrm{L})$ was plated on an agar plate and incubated at $37{ }^{\circ} \mathrm{C}$ for $24 \mathrm{~h}$ before the bacteria colonies were counted.

\section{Electron microscopy measurement}

Scanning electron microscopy (SEM) was performed to investigate the morphological changes of E. coli and S. aureus upon laser irradiation by following a reported procedure. ${ }^{10}$ The bacteria were incubated with $\mathrm{Bi}_{2} \mathrm{Se}_{3}$ NPs/PEI $(80 \mathrm{ppm})$ and irradiated for 10 min using an $808 \mathrm{~nm}$ laser. After irradiation the control and irradiated bacteria were centrifuged and the supernatant was discarded. The bacterial pellet was dispersed and fixed with formaldehyde (4\%) for $30 \mathrm{~min}$, then dehydrated and sputter coated with platinum, ready for SEM imaging.

\section{Fluorescence assay}

After irradiation, the control and irradiated bacteria were stained with PI $\left(10 \mu \mathrm{g} \mathrm{mL}^{-1}\right)$ for $10 \mathrm{~min}$ and stained with DAPI $\left(3 \mu \mathrm{g} \mathrm{mL}{ }^{-1}\right)$ for $5 \mathrm{~min}$ in the dark. The live and dead bacteria were visualized with a CLSM confocal microscope (Zeiss, LSM 700).

\section{Assessment of photocatalytic activity}

The photocatalytic activity of the as-prepared $\mathrm{Bi}_{2} \mathrm{Se}_{3} \mathrm{NPs} / \mathrm{PEI}$ was evaluated by the degradation of organic pollutants, MB and RhB dyes, under NIR light irradiation. The aqueous stock solutions of $\mathrm{MB}$ and $\mathrm{RhB}\left(10 \mu \mathrm{g} \mathrm{mL}^{-1}\right)$ in DI water were prepared. Then, $\mathrm{Bi}_{2} \mathrm{Se}_{3} \mathrm{NPs} / \mathrm{PEI}(5 \mathrm{mg})$ was added to the MB and $\mathrm{RhB}$ solutions $(20 \mathrm{~mL})$ and the suspensions were sonicated for $5 \mathrm{~min}$, followed by stirring for $30 \mathrm{~min}$ in a dark environment to allow equilibrium of adsorption/desorption. The obtained suspensions were examined under NIR light irradiation $(300 \mathrm{~W}$ high pressure halogen lamp, 700-1000 nm wavelength region). In this experiment the $808 \mathrm{~nm}$ laser was replaced by a halogen lamp because the former had a small laser spot which cannot be expanded, leading to experimental difficulties in covering the whole area of the vessel $\left(20 \mathrm{~mL}\right.$ contents with dyes and $\mathrm{Bi}_{2} \mathrm{Se}_{3}$ NPs/PEI). The average temperature during the experiments was maintained at $30^{\circ} \mathrm{C}$. Total irradiation time was $3 \mathrm{~h}$ and $4 \mathrm{~h}$ for $\mathrm{MB}$ and RhB, respectively. At every $30 \mathrm{~min}$ interval, a suspension solution $(2.5 \mathrm{~mL})$ was taken from the reacting suspension, centrifuged, and the UV-vis absorbance spectrum was recorded (Model Lambda 35, Perkin-Elmer). The as-prepared $\mathrm{Bi}_{2} \mathrm{Se}_{3} \mathrm{NPs} /$ PEI was recovered from the suspension by centrifugation at $6000 \mathrm{rpm}$ for $4 \mathrm{~min}$ and reused to determine the efficiency. The same experiments were carried out by adding $10 \mu \mathrm{g} \mathrm{mL} \mathrm{L}^{-1}$ of each organic dye into a tap water sample. The percentage of dye degradation was calculated by the following formula:

$$
\text { Dye degradation }(\%)=\left[\left(C_{0}-C_{t} / C_{0}\right)\right] \times 100
$$

where $C_{0}$ is the initial concentration of the $\mathrm{MB}$ and $\mathrm{RhB}$ solutions and $C_{t}$ is the concentration of the dye solution after $30 \mathrm{~min}$ of NIR light irradiation.

\section{The photocatalytic stability test}

A photocatalytic stability of $\mathrm{Bi}_{2} \mathrm{Se}_{3}$ NPs/PEI experiment was performed. Herein, after completion of the photocatalytic reaction, the photocatalyst was centrifuged. The residue was 
collected and subsequently washed with DI water and ethanol, and dried in an oven at $60{ }^{\circ} \mathrm{C}$. The recycled photocatalyst was reused for a second cycle of the degradation study with fresh $\mathrm{MB}$ and $\mathrm{RhB}$ solutions. This process was repeated 3 times.

\section{Results and discussion}

\section{Characterization}

The morphologies and nanostructures of the as-prepared $\mathrm{Bi}_{2} \mathrm{Se}_{3}$ NPs were investigated by scanning electron microscopy (SEM) and transmission electron microscopy (TEM). The SEM images (Fig. 1a and b) depicted the layered structure of the $\mathrm{Bi}_{2} \mathrm{Se}_{3}$ NPs with an average size within $0.8-0.9 \mu \mathrm{m}$. The NPs appeared with good hexagonal morphology with a planar dimension, and some were formed in an intermediate stage and showed truncated trigonal morphology. The curves and outlines of overlap between two nanoplates in the image could be clearly distinguished. The hexagonal morphology of the $\mathrm{Bi}_{2} \mathrm{Se}_{3}$ NPs was further confirmed by low magnification bright field TEM (Fig. 1c), and $\mathrm{Bi}_{2} \mathrm{Se}_{3} \mathrm{NPs}$ form a layered chalcogenide with a rhombohedral crystal structure (inset in Fig. 1b).

The selected area electron diffraction (SAED) pattern (Fig. 1d) can be indexed to have 6-fold symmetry with a [001] zone axis pattern, which is in good agreement with a previous report. ${ }^{38}$ Energy dispersive X-ray analysis (EDXA) was performed to determine the chemical composition of the $\mathrm{Bi}_{2} \mathrm{Se}_{3} \mathrm{NPs}$. The EDXA mapping (Fig. S1a-c $\dagger$ ) confirmed the presence of Bi and Se elements with an approximate atomic ratio of $2: 3$. The EDXA spectrum (Fig. S1d $\dagger$ ) also confirmed the presence of Bi with peaks at 1.9 and $2.52 \mathrm{keV}$, and Se with a peak at $1.47 \mathrm{keV}$. Additionally, the powder XRD pattern (Fig. 2a) correlated well with the standard $\mathrm{Bi}_{2} \mathrm{Se}_{3}$ pattern (JCPDS no. 89-2008) and

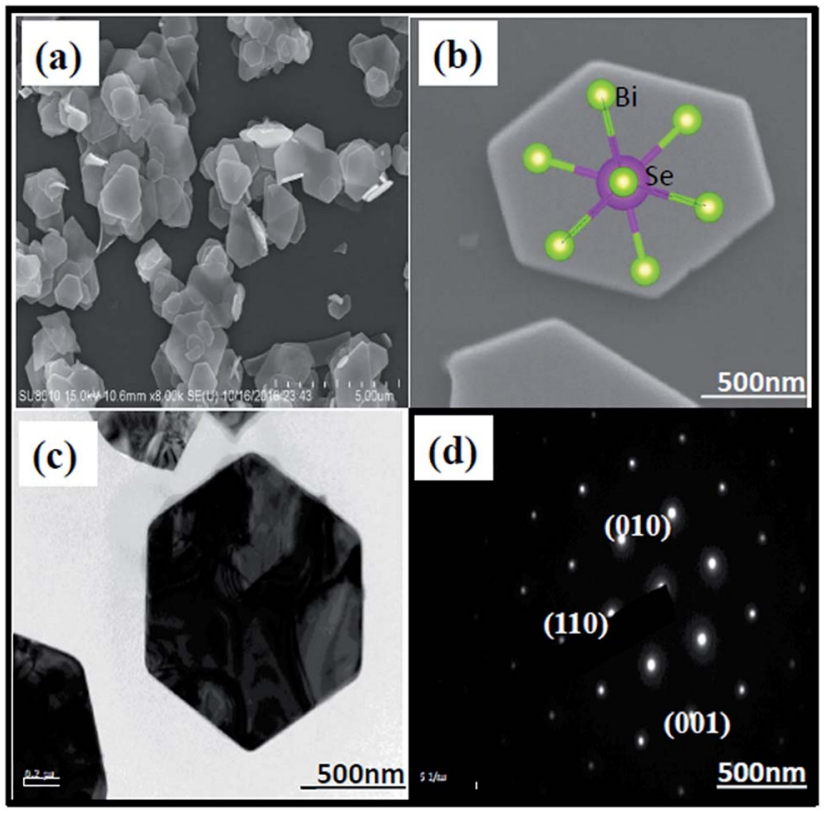

Fig. 1 Images of $\mathrm{Bi}_{2} \mathrm{Se}_{3} \mathrm{NPs}$ : (a) SEM image under low magnification, (b) high magnification (inset demonstrating the rhombohedral crystal structure), (c) TEM image, and (d) SAED image.
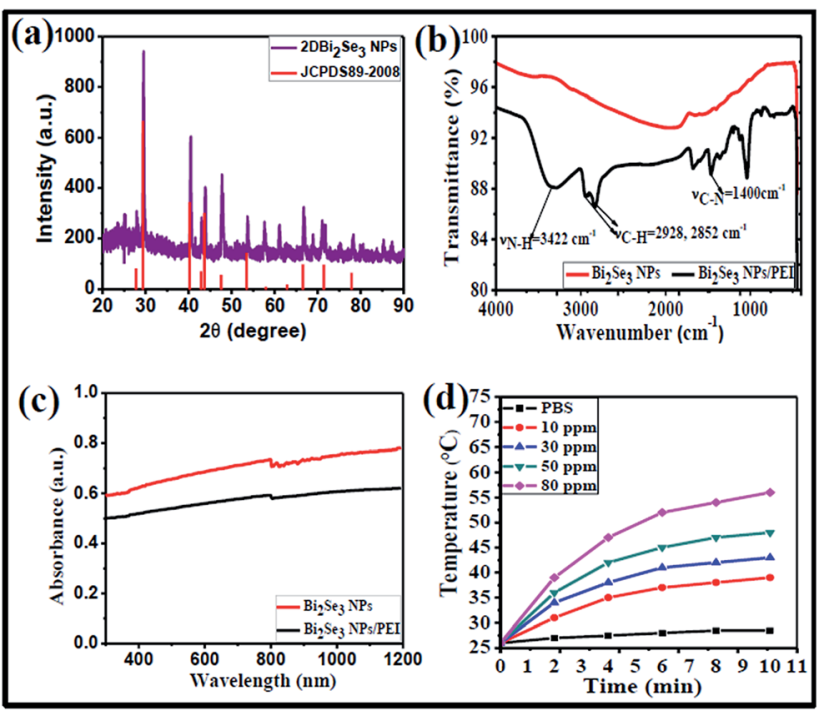

Fig. 2 The spectra of $\mathrm{Bi}_{2} \mathrm{Se}_{3} \mathrm{NPs}$ : (a) powder XRD, (b) FTIR, (c) UV-visNIR absorption, and (d) temperature profiles of $\mathrm{Bi}_{2} \mathrm{Se}_{3} \mathrm{NPs} / \mathrm{PEI}$ at different concentrations upon exposure to $808 \mathrm{~nm}$ NIR light at $1 \mathrm{~W}$ $\mathrm{cm}^{-2}$.

exhibited characteristic diffraction peaks at $2 \theta=30.1^{\circ}, 41.3^{\circ}$, $44.5^{\circ}, 48.7^{\circ}, 67.6^{\circ}$, and $79.7^{\circ}$, which can be indexed to the (101), (015), (1010), (110), (0015), (1115), and (222) planes of $\mathrm{Bi}_{2} \mathrm{Se}_{3}$ NPs, respectively. These results were in accordance with a previous report. ${ }^{37}$

In order to achieve good water dispersibility, the surface of $\mathrm{Bi}_{2} \mathrm{Se}_{3}$ NPs was wrapped with a cationic polymer, polyethyleneimine (PEI), via electrostatic interactions. The successful surface modification was confirmed by Fourier transform infrared (FTIR) spectra (Fig. 2b). The $\mathrm{Bi}_{2} \mathrm{Se}_{3} \mathrm{NPs} / \mathrm{PEI}$ exhibited bands at 3422,2928 , and $2852 \mathrm{~cm}^{-1}$, which are attributed to $\mathrm{N}-\mathrm{H}, \mathrm{C}-\mathrm{H}$, and $\mathrm{C}-\mathrm{H}$ vibrational frequencies, respectively; whereas $\mathrm{Bi}_{2} \mathrm{Se}_{3} \mathrm{NPs}$ did not show any characteristic vibrational frequencies. In addition, the presence of the C-N stretching frequency at $1400 \mathrm{~cm}^{-1}$ revealed the existence of abundant amine groups in the $\mathrm{Bi}_{2} \mathrm{Se}_{3}$ NPs/PEI. ${ }^{39}$ Furthermore, zeta-potential measurements (Fig. S2a†) indicated that the negatively charged surface of $\mathrm{Bi}_{2} \mathrm{Se}_{3} \mathrm{NPs}(-33.2$ $\pm 2.56 \mathrm{mV}$ ) is converted to a positively charged surface ( $35 \pm 2.56$ $\mathrm{mV}$ ) after wrapping with PEI. These results evidence the successful wrapping of $\mathrm{Bi}_{2} \mathrm{Se}_{3}$ NPs with PEI. The as-prepared $\mathrm{Bi}_{2} \mathrm{Se}_{3} \mathrm{NPs} / \mathrm{PEI}$ exhibited good dispersibility in water as well as in phosphate buffered solution (PBS) (Fig. S2b(i-iv) †). The optical properties of $\mathrm{Bi}_{2} \mathrm{Se}_{3} \mathrm{NPs}$ and $\mathrm{Bi}_{2} \mathrm{Se}_{3} \mathrm{NPs} / \mathrm{PEI}$ were investigated with UV-vis-NIR spectra ranging from 300-1200 nm (Fig. 2c), both exhibiting high absorbance in the range of interest, from 700 to $1200 \mathrm{~nm}$, supporting their potential NIR light-induced properties.

\section{NIR light mediated properties}

Owing to the high absorbance in the NIR region, the photothermal properties of $\mathrm{Bi}_{2} \mathrm{Se}_{3} \mathrm{NPs}$ and different concentrations of $\mathrm{Bi}_{2} \mathrm{Se}_{3} \mathrm{NPs} / \mathrm{PEI}$ were investigated upon irradiation with an $808 \mathrm{~nm}$ laser at $1 \mathrm{~W} \mathrm{~cm}^{-2}$ for $10 \mathrm{~min}$. The temperature elevation profile of both $\mathrm{Bi}_{2} \mathrm{Se}_{3}$ NPs and $\mathrm{Bi}_{2} \mathrm{Se}_{3}$ NPs/PEI (Fig. S3a $\dagger$ ) 
exhibited high and concentration dependent photothermal effects. Detailed temperature profiles of $\mathrm{Bi}_{2} \mathrm{Se}_{3}$ NPs/PEI at different concentrations (Fig. 2d) showed that the temperature was elevated with increasing $\mathrm{Bi}_{2} \mathrm{Se}_{3} \mathrm{NPs} / \mathrm{PEI}$ concentration and the highest tested concentration of $80 \mathrm{ppm}$ elevated the temperature to $56^{\circ} \mathrm{C}$. This temperature is sufficient enough to cause the ablation of bacteria by inhibiting essential intracellular reactions and denaturing proteins/enzymes. ${ }^{\mathbf{1 0 , 1 2}}$ Further-

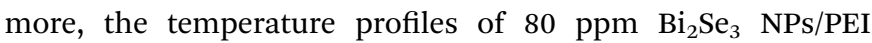
irradiated with an $808 \mathrm{~nm}$ laser at $(0.5,1.0$ and 1.5$) \mathrm{W} \mathrm{cm}^{-2}$ for $10 \mathrm{~min}$ (Fig. $\mathrm{S} 3 \mathrm{~b} \dagger$ ) also revealed that the temperature elevates with increased power density. In addition, the photothermal conversion efficiency $(\eta)$ of $\mathrm{Bi}_{2} \mathrm{Se}_{3} \mathrm{NPs} / \mathrm{PEI}$ was calculated as $32.07 \%$. The results indicated that $\mathrm{Bi}_{2} \mathrm{Se}_{3}$ NPs/PEI can be effectively used as a photothermal therapy reagent.

Some metal chalcogenide nanoparticles have been reported to function as photothermal agents and generate singlet oxygen $\left({ }^{1} \mathrm{O}_{2}\right)$ upon laser irradiation and act as PDT agents. ${ }^{17} \mathrm{We}$ therefore investigated the ${ }^{1} \mathrm{O}_{2}$ generation ability of $\mathrm{Bi}_{2} \mathrm{Se}_{3} \mathrm{NPs} /$ PEI upon irradiation by an $808 \mathrm{~nm}$ laser by measuring the change in the absorbance of 1,3-diphenylisobenzofuran (DPBF). DPBF is known to bleach via an oxidation reaction with ${ }^{1} \mathrm{O}_{2}$ to form an endoperoxide product, and thus can be used as an indicator for ${ }^{1} \mathrm{O}_{2}$ generation. ${ }^{18}$ The change in the absorbance of DPBF as a function of irradiation time in the presence/absence of NIR light was shown in Fig. S5. $\dagger$ The results reveals that in the absence of light there is no significant change in the absorbance of DPBF (Fig. S5a and $\mathrm{c}^{\dagger}$ ). However, in the presence of light both samples containing $\mathrm{Bi}_{2} \mathrm{Se}_{3} \mathrm{NPs} / \mathrm{PEI}$ and $\mathrm{Bi}_{2} \mathrm{Se}_{3} \mathrm{NPs}$ exhibited a steady drop in absorbance of DPBF at $410 \mathrm{~nm}$ with increased irradiation time (Fig. S5b and $\mathrm{c} \dagger$ ), indicating that the bleaching was caused by ${ }^{1} \mathrm{O}_{2}$. These results confirm the ${ }^{1} \mathrm{O}_{2}$ generation ability of both $\mathrm{Bi}_{2} \mathrm{Se}_{3}$ NPs and $\mathrm{Bi}_{2} \mathrm{Se}_{3}$ NPs/PEI.

However, the ${ }^{1} \mathrm{O}_{2}$ generation efficiency of $\mathrm{Bi}_{2} \mathrm{Se}_{3}$ NPs was slightly less than that of $\mathrm{Bi}_{2} \mathrm{Se}_{3}$ NPs/PEI (Fig. S5c $\dagger$ ), and was attributed to the poor water solubility of $\mathrm{Bi}_{2} \mathrm{Se}_{3}$ NPs. These results indicate that $\mathrm{Bi}_{2} \mathrm{Se}_{3}$ NPs/PEI has potential for use in PDT. The potential of the ${ }^{1} \mathrm{O}_{2}$ generation ability of $\mathrm{Bi}_{2} \mathrm{Se}_{3} \mathrm{NPs} /$ PEI was further tested with bacteria solutions. The 2,7dichlorofluorescein diacetate (DCFH-DA) fluorescent probe was used to test for the presence of ${ }^{1} \mathrm{O}_{2}$ inside bacteria. When the bacterial solution was irradiated by an $808 \mathrm{~nm}$ laser, some green fluorescence of DCFH-DA was observed (Fig. S6a and $b \dagger$ ), indicating that $\mathrm{Bi}_{2} \mathrm{Se}_{3}$ NPs/PEI can generate ROS upon irradiation by an $808 \mathrm{~nm}$ laser. ROS can destroy the cytoplasmic membrane and lead to DNA destruction, resulting in effective killing of bacteria. To the best of our knowledge, this is the first demonstration of the ROS generation ability of $\mathrm{Bi}_{2} \mathrm{Se}_{3} \mathrm{NPs}$ upon NIR light excitation.

\section{NIR light mediated dual-modal antibacterial activity}

Inspired by the photoirradiation results, we evaluated the effect of photoirradiation in the use of PTT and PDT together in the killing of $S$. aureus and $E$. coli, which were first incubated with different concentrations of $\mathrm{Bi}_{2} \mathrm{Se}_{3} \mathrm{NPs} / \mathrm{PEI}$ for $30 \mathrm{~min}$ followed by photoirradiation using an $808 \mathrm{~nm}$ laser for $10 \mathrm{~min}$. The photoirradiation killing effect on the bacteria was determined by a colony counting method on agar plates after incubation for $24 \mathrm{~h}$. The photoirradiation killing effect (Fig. 3 and $\mathrm{S} 4 \dagger$ ) was dependent on both the $\mathrm{Bi}_{2} \mathrm{Se}_{3}$ NPs/PEI concentrations and laser power intensities. The killing efficiency was directly proportional to the concentration of $\mathrm{Bi}_{2} \mathrm{Se}_{3}$ NPs/PEI and more than $97 \%$ of both $S$. aureus and E. coli were killed at $80 \mathrm{ppm}$ which was attributed to the strong PTT effect and ${ }^{1} \mathrm{O}_{2}$ generation ability. The absence of either the laser or the $\mathrm{Bi}_{2} \mathrm{Se}_{3}$ NPs/PEI did not cause significant bacteria death, proving that the observed bacterial killing proceeds via the photothermal effect and the generation of ${ }^{1} \mathrm{O}_{2}$.

The extent of the respective and combined effect of PDT and PTT on bacterial death was evaluated. An irradiation experiment was performed at $4{ }^{\circ} \mathrm{C}$ (to minimize the PTT effect) to estimate the contribution from PDT alone under the assumption that the PDT effect is independent of the incubation temperature. A series of bacterial solutions containing different concentrations of $\mathrm{Bi}_{2} \mathrm{Se}_{3} \mathrm{NPs} / \mathrm{PEI}$ ranging from 10 to $80 \mathrm{ppm}$ were prepared and tested for their bacterial killing effects. Using the bacteria plate count method without the laser, with the laser at $4{ }^{\circ} \mathrm{C}$ and with the laser at room temperature conditions, the contributions from the laser, PDT, and PDT + PTT were evaluated for their effect on bacteria death respectively. The obtained results indicated that the killing efficiency of PDT alone was $\sim 21 \%$ and $\sim 19 \%$ for $S$. aureus (Fig. 3a) and E. coli (Fig. 3b), respectively. In addition, the killing efficiency of PTT alone was obtained from the difference between the killing efficiency of PTT + PDT and PDT alone, which was $\sim 78 \%$ and $\sim 76 \%$ for $S$. aureus and $E$. coli, respectively.

To further verify the bacterial survival rate upon laser irradiation, a fluorescence-based bacterial viability assay ${ }^{\mathbf{1 0}}$ was conducted. Briefly, propidium iodide (PI) was used for the labelling of dead bacteria with red fluorescence; whereas 4,6diamidino 2-phenylindole (DAPI) was used for live bacteria labelling with blue fluorescence. The fluorescence images of $S$. aureus (Fig. 4a) and E. coli (Fig. 4c) clearly evidence an abundant number of DAPI-labelled live bacteria in the absence of PTT + PDT. Meanwhile, PI-labelled dead bacteria became more obvious in the $\mathrm{Bi}_{2} \mathrm{Se}_{3}$ NPs/PEI solution (Fig. $4 \mathrm{~b}$ and d) after 10 minutes of

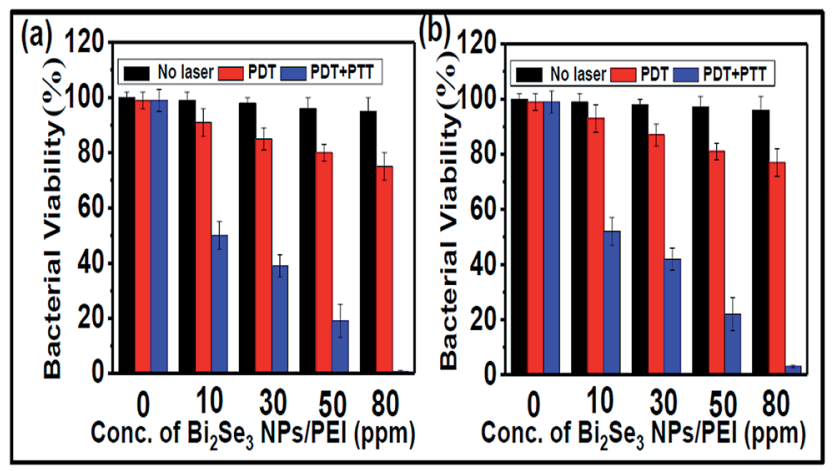

Fig. 3 Bacterial viability in percentage under PDT alone and PTT + PDT for (a) S. aureus and (b) E. coli in comparison to the control (no laser). 

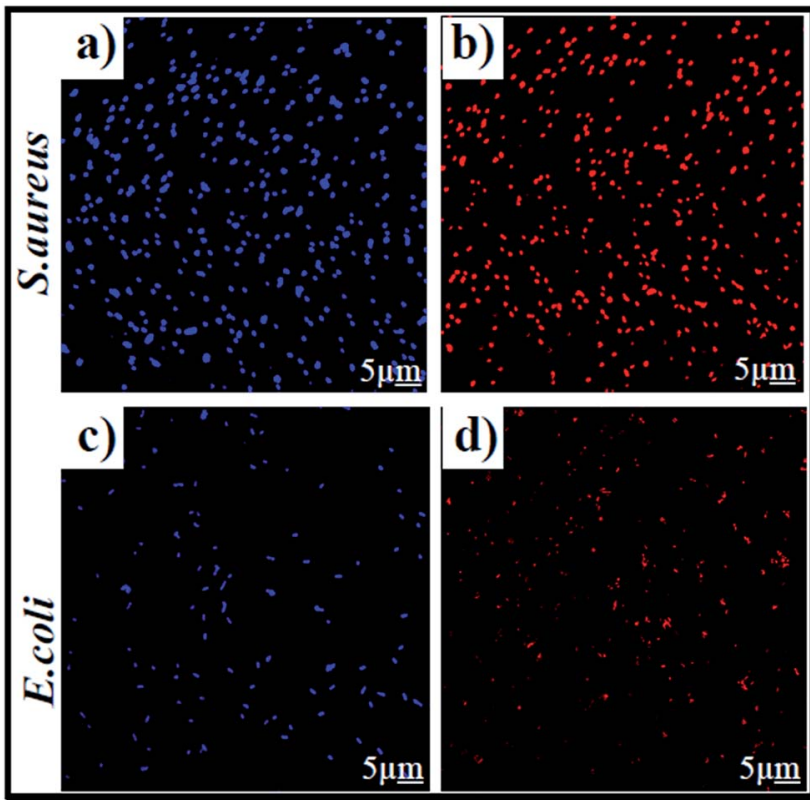

Fig. 4 Fluorescence microscopy (confocal) images showing the PTT and PDT cytotoxicity for $S$. aureus and $E$. coli after 10 minutes of irradiation by an $808 \mathrm{~nm}$ laser at $1 \mathrm{~W} \mathrm{~cm}{ }^{-2}$ with the $\mathrm{Bi}_{2} \mathrm{Se}_{3} \mathrm{NPs} / \mathrm{PEl}$ control ( $\mathrm{a}$, $c)$ and the combined PTT and PDT effect on the bacteria (b, d).

irradiation by an $808 \mathrm{~nm}$ laser. SEM images were also taken to evaluate the morphological changes of both $S$. aureus and E. coli before and after treatment with $\mathrm{Bi}_{2} \mathrm{Se}_{3}$ NPs/PEI. The control $S$. aureus and $E$. coli retained a complete and undamaged roundshape (Fig. 5a) and rod-shape (Fig. 5c) structure, respectively. However, the $\mathrm{Bi}_{2} \mathrm{Se}_{3} \mathrm{NPs} / \mathrm{PEI}+\mathrm{NIR}$ treated bacteria (Fig. $5 \mathrm{~b}$ and d)

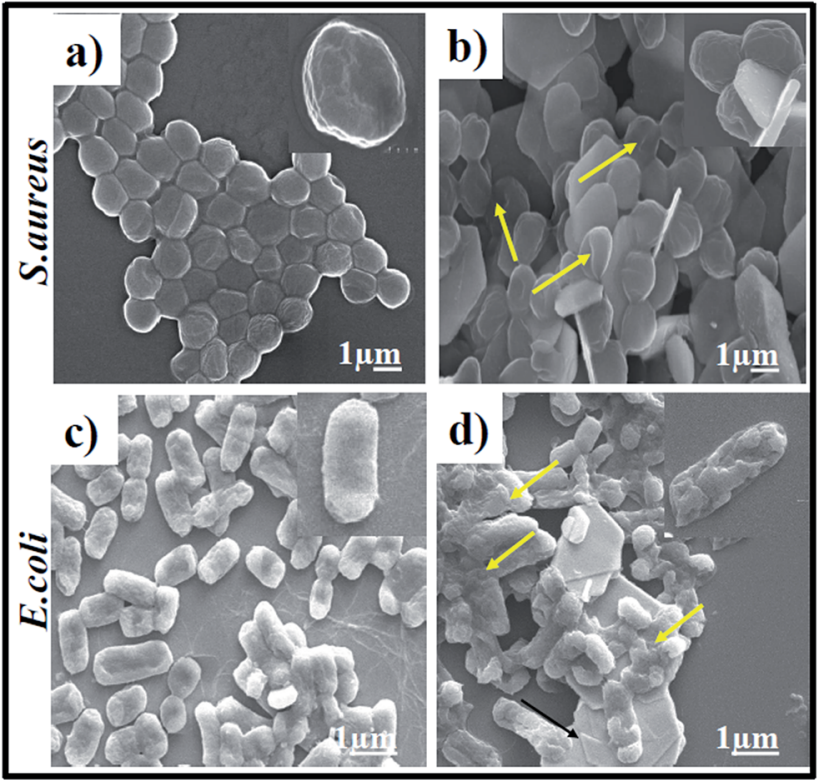

Fig. 5 SEM images of $S$. aureus ((a) control, (b) $\mathrm{Bi}_{2} \mathrm{Se}_{3} \mathrm{NPS} / \mathrm{PEI}+\mathrm{NIR}$ ); E. coli ((c) control, (d) $\mathrm{Bi}_{2} \mathrm{Se}_{3} \mathrm{NPs} / \mathrm{PEI}+\mathrm{NIR}$ ) (conc. of $\mathrm{Bi}_{2} \mathrm{Se}_{3} \mathrm{NPs} / \mathrm{PEI}=$ 80 ppm, $808 \mathrm{~nm}$ laser, $\left.1 \mathrm{~W} \mathrm{~cm}^{-2}, 10 \mathrm{~min}\right)$. The yellow arrow highlights the damaged and groove-like structures. both exhibited a damaged and groove-like structure. The excellent capturing capability towards both bacteria walls of $\mathrm{Bi}_{2} \mathrm{Se}_{3}$ NPs/PEI is presumably due to the positive charge of PEI. In combination with the improved PDT and PTT effects upon NIR light irradiation, the obtained results show that the $\mathrm{Bi}_{2} \mathrm{Se}_{3}$ NPs/PEI material acts as a promising PDT + PTT agent in comparison to some other reported materials (Table $\mathrm{S} 1 \dagger$ ).

\section{Photocatalytic degradation of $\mathrm{MB}$ and $\mathrm{RhB}$}

The photocatalytic activities of $\mathrm{Bi}_{2} \mathrm{Se}_{3} \mathrm{NPs}$ and $\mathrm{Bi}_{2} \mathrm{Se}_{3} \mathrm{NPs} / \mathrm{PEI}$ were investigated based on the degradation of model organic pollutants such as MB and RhB dyes under NIR light irradiation. The photodegradation activities were monitored by measuring the absorbances at the characteristic wavelengths of $\sim 664 \mathrm{~nm}$ and $\sim 540 \mathrm{~nm}$ for $\mathrm{MB}$ and $\mathrm{RhB}$, respectively. A comparison study between the control group (i.e. dyes with $\mathrm{Bi}_{2} \mathrm{Se}_{3} \mathrm{NPs} / \mathrm{PEI}$ in the dark) and experimental groups (i.e. dyes with NIR light $+\mathrm{Bi}_{2} \mathrm{Se}_{3} \mathrm{NPs} / \mathrm{PEI}$ ) was performed based on the respective degradation rates. The obtained time-evolved UV-vis spectra of MB and RhB demonstrate that $\mathrm{Bi}_{2} \mathrm{Se}_{3}$ NPs/PEI in the dark did not induce any significant changes in the absorbances of MB or RhB (Fig. S7a and c $\dagger$ ). However, for the groups treated with NIR light decreases in the absorbances of MB at $664 \mathrm{~nm}$ and $\mathrm{RhB}$ at $540 \mathrm{~nm}$ with increasing irradiation time were observed (Fig. S7b and $\mathrm{d} \dagger$ ), demonstrating the photocatalytic activity of $\mathrm{Bi}_{2} \mathrm{Se}_{3}$ NPS/PEI on MB and RhB. To estimate the residual concentrations of $\mathrm{MB}$ and $\mathrm{RhB}$ dyes after photodegradation, the $C / C_{0}$ ratio was plotted $v s$. the irradiation time, where $C$ and $C_{0}$ are the concentrations of the dyes at a time $t$ and $t=0$, respectively. The results reveal that the decrease in concentration of both MB (Fig. 6a) and RhB (Fig. 6b) is negligible when treated with $\mathrm{Bi}_{2} \mathrm{Se}_{3}$ NPs/PEI in the dark. However, when treated with NIR $+\mathrm{Bi}_{2} \mathrm{Se}_{3} \mathrm{NPs}$ or NIR $+\mathrm{Bi}_{2} \mathrm{Se}_{3} \mathrm{NPs} / \mathrm{PEI}$, the

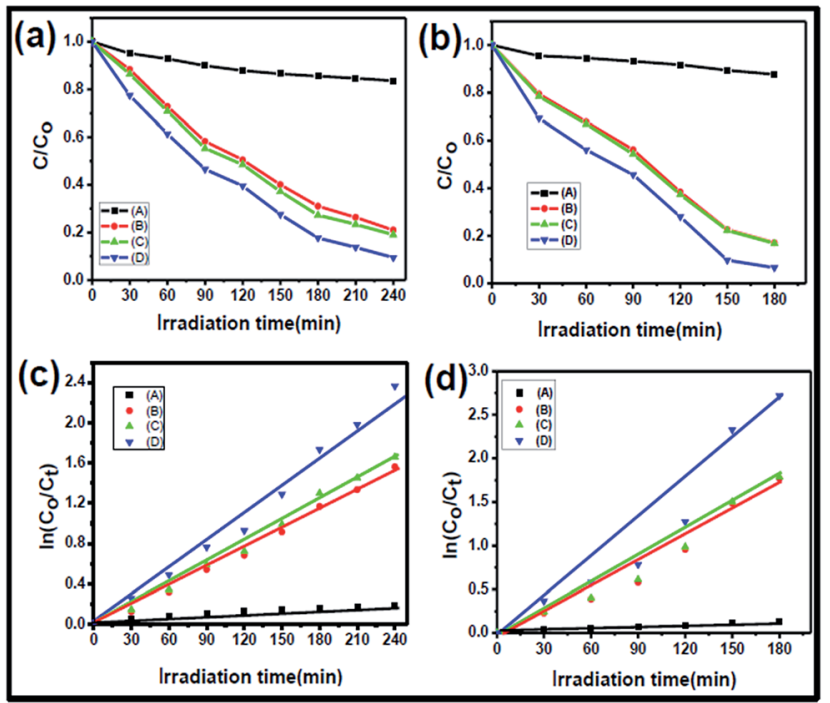

Fig. 6 (a) Dye + $\mathrm{Bi}_{2} \mathrm{Se}_{3} \mathrm{NPs} / \mathrm{PEI}$, (b) dye $+\mathrm{Bi}_{2} \mathrm{Se}_{3} \mathrm{NPs}+\mathrm{NIR}$ light, (c) dye $+\mathrm{Bi}_{2} \mathrm{Se}_{3} \mathrm{NPs} / \mathrm{PEI}+\mathrm{NIR}$ light, and (d) dye + $\mathrm{Bi}_{2} \mathrm{Se}_{3} \mathrm{NPs} / \mathrm{PEI}$. All in DI water except (C) in tap water; photocatalytic degradation of (A) MB and (B) RhB. Reaction kinetics for (C) MB and (D) RhB. 
degradation of both $\mathrm{MB}$ and $\mathrm{RhB}$ increases significantly with increasing irradiation time. Degradation rates of $~ 95 \%$ for $\mathrm{MB}$ and $\sim 93 \%$ for RhB were found after $3 \mathrm{~h}$ and $4 \mathrm{~h}$, respectively. Both solutions became faded. The kinetic data for photodegradation of $\mathrm{MB}$ and $\mathrm{RhB}$ in the presence of $\mathrm{Bi}_{2} \mathrm{Se}_{3} \mathrm{NPs}$ and $\mathrm{Bi}_{2} \mathrm{Se}_{3} \mathrm{NPS} / \mathrm{PEI}$ were investigated corresponding to the Langmuir-Hinshelwood model. ${ }^{40}$ The degradation kinetics data were fitted with a pseudo-first order kinetic equation, where $C_{0}$ and $C_{t}$ are the initial concentrations of $\mathrm{MB}$ and $\mathrm{RhB}$ before irradiation and at any time $t$ under light irradiation respectively, and $k$ is the apparent rate constant $\left(\mathrm{min}^{-1}\right)$. The regression curves of $\ln \left(C_{0} / C_{t}\right)$ vs. $t$ were straight lines, indicating pseudofirst order kinetics, which can describe the photocatalytic degradation of MB and RhB (Fig. 6c and d). Nevertheless, the $\mathrm{Bi}_{2} \mathrm{Se}_{3}$ NPs exhibited slightly less photocatalytic activity than $\mathrm{Bi}_{2} \mathrm{Se}_{3} \mathrm{NPs} / \mathrm{PEI}$, ascribed to its poor water solubility.

$$
\ln \left(C_{0} / C_{t}\right)=k t
$$

Furthermore, to investigate the ability of the $\mathrm{Bi}_{2} \mathrm{Se}_{3} \mathrm{NPs} / \mathrm{PEI}$ nanocomposites for removal of organic dyes from water, we added $10 \mu \mathrm{g} \mathrm{mL}{ }^{-1}$ of each organic dye into tap water samples. The effect of the presence of common anions such as sulfate, carbonate, and bicarbonate on the photocatalytic degradation of organic dyes is shown in Fig. 6c. It is observed that the rate of degradation decreases in the presence of anions, which may be due to inhibition of hydroxyl radicals. ${ }^{41}$ These anions may hinder the active sites on the $\mathrm{Bi}_{2} \mathrm{Se}_{3}$ NPs surface.

The schematic of the mechanism for the photodegradation of $\mathrm{MB}$ and $\mathrm{RhB}$ with NIR $+\mathrm{Bi}_{2} \mathrm{Se}_{3}$ NPs/PEI (Fig. S8 $\dagger$ ) illustrates that when a mixed solution of the photocatalyst and dyes is irradiated with NIR light with 700-1000 $\mathrm{nm}$ wavelength, the $\mathrm{e}^{-}$ in the VB is excited to the CB of the $\mathrm{Bi}_{2} \mathrm{Se}_{3} \mathrm{NPs} / \mathrm{PEI}$. The excited $\mathrm{e}^{-}$will react with the adsorbed $\mathrm{O}_{2}$ molecules and form $\cdot \mathrm{O}_{2}{ }^{-}$ radicals. ${ }^{35}$ Alternatively, the $\mathrm{h}^{+}$in the VB of the $\mathrm{Bi}_{2} \mathrm{Se}_{3} \mathrm{NPs}$ are taken by $\mathrm{OH}^{-}$derived from the aqueous solution and form $\cdot \mathrm{OH}$ radicals in the mixed solution. These radicals, $\mathrm{O}_{2}{ }^{-}$and $\cdot \mathrm{OH}$, act as oxidizing agents and react with both dye molecules and decompose them into $\mathrm{CO}_{2}, \mathrm{H}_{2} \mathrm{O}$, and other small molecules, ${ }^{\mathbf{4 2 - 4 5}}$ avoiding the recombination of $\mathrm{h}^{+}$and $\mathrm{e}^{-}$during the photocatalytic process. The complete degradation process of $\mathrm{MB}$ and $\mathrm{RhB}$ in the presence of $\mathrm{Bi}_{2} \mathrm{Se}_{3} \mathrm{NPs} / \mathrm{PEI}$ as a photocatalyst may be explained with the help of the following equations:

$$
\begin{aligned}
& \mathrm{Bi}_{2} \mathrm{Se}_{3} \mathrm{NPs} / \mathrm{PEI}+\text { photons }(h \nu, 700-1100 \mathrm{~nm}) \rightarrow \\
& \left(\mathrm{e}^{-}\right) \mathrm{CB}+\left(\mathrm{h}^{+}\right) \mathrm{VB} \\
& \mathrm{H}_{2} \mathrm{O}+\mathrm{h}^{+} \rightarrow \mathrm{OH}^{-}+\mathrm{H}^{+} \\
& \mathrm{OH}^{-}+\mathrm{h}^{+} \rightarrow \cdot \mathrm{OH} \text { (radical) } \\
& \mathrm{O}_{2}+\mathrm{e}^{-} \rightarrow \mathrm{O}_{2}^{-\cdot} \text { (radical) }
\end{aligned}
$$

$\mathrm{MB} / \mathrm{RhB}+\left(\mathrm{Bi}_{2} \mathrm{Se}_{3} \mathrm{NPs} / \mathrm{PEI}\right)+\mathrm{O}_{2}{ }^{-\cdot} \rightarrow$ degradation products was monitored at 660 to $664 \mathrm{~nm}$ and $540 \mathrm{~nm}$, respectively. $\mathrm{MB}$ / $\mathrm{RhB}+\left(\mathrm{Bi}_{2} \mathrm{Se}_{3} \mathrm{NPs} / \mathrm{PEI}\right)+{ }^{\circ} \mathrm{OH} \rightarrow$ degradation products was monitored at 660 to $664 \mathrm{~nm}$ and $540 \mathrm{~nm}$, respectively.
In addition to the photocatalytic activity, the stability of photocatalysts is also very important for practical applications. Reusability was evaluated by using a recycling test of the photocatalytic degradation of $\mathrm{MB}$ and $\mathrm{RhB}$ in four repeated cycles using $\mathrm{Bi}_{2} \mathrm{Se}_{3}$ NPs and $\mathrm{Bi}_{2} \mathrm{Se}_{3}$ NPs/PEI under identical experimental conditions. The results showed that the degradation efficiency for $\mathrm{Bi}_{2} \mathrm{Se}_{3}$ NPs/PEI was $\sim 91$ and $\sim 89 \%$ for MB and RhB, respectively, after four cycles which was $\sim 10 \%$ better than that of the $\mathrm{Bi}_{2} \mathrm{Se}_{3}$ NPs (Fig. S9 $\dagger$ ), and this suggests that the prepared $\mathrm{Bi}_{2} \mathrm{Se}_{3}$ NPs/PEI possessed good activity and stability. Further, the SEM indicated that there were no observable morphological changes in the recycled photocatalyst (Fig. S10†). Moreover, the photodegradation efficiency of the recycled photocatalysts were investigated and it was observed that there were no significant changes (Fig. S9†). Good photocatalytic activity in the degradation of dyes with remarkable stability demonstrates that $\mathrm{Bi}_{2} \mathrm{Se}_{3} \mathrm{NPs} / \mathrm{PEI}$ could act as a reliable photocatalyst in comparison to other reported materials (Table $\mathrm{S} 2 \dagger$ ). To the best of our knowledge, this is the first demonstration of the NIR light mediated photocatalytic ability of $\mathrm{Bi}_{2} \mathrm{Se}_{3}$ NPs.

\section{Conclusions}

In summary, we have engineered a novel material, $\mathrm{Bi}_{2} \mathrm{Se}_{3} \mathrm{NPs} / \mathrm{PEI}$, that can be used as a NIR light activated dual-modal phototherapeutic agent for eradication of pathogenic bacteria as well as for photodegradation of organic pollutants. The developed $\mathrm{Bi}_{2} \mathrm{Se}_{3}$ NPs/PEI exhibited good hexagonal morphology with a planar dimension. Also, the $\mathrm{Bi}_{2} \mathrm{Se}_{3}$ NPs/PEI demonstrated excellent absorption characteristics in the NIR wavelength region. The photothermal conversion efficiency of $\mathrm{Bi}_{2} \mathrm{Se}_{3}$ NPs/PEI was calculated as $32.07 \%$. The $\mathrm{Bi}_{2} \mathrm{Se}_{3}$ NPs/PEI also generated singlet oxygen upon NIR laser irradiation. Furthermore, the dual-modal phototherapeutic effects mediated by $\mathrm{Bi}_{2} \mathrm{Se}_{3}$ NPs/PEI induced high percentages of bacterial cellular deaths for both $E$. coli $(97 \%$ at 80 ppm) and S. aureus (99\% at $80 \mathrm{ppm})$. The relative contributions of PTT and PDT were found to be near to a $4: 1$ ratio in killing both bacteria. To the best of our knowledge, this is the first report that demonstrates the photodynamic therapeutic abilities of $\mathrm{Bi}_{2} \mathrm{Se}_{3}$ $\mathrm{NPs} / \mathrm{PEI}$ in killing pathogenic bacteria. In addition, $\mathrm{Bi}_{2} \mathrm{Se}_{3} \mathrm{NPs} /$ PEI also showed good NIR light activated photocatalytic properties for the degradation of organic pollutants such as MB and RhB. The degradation efficiencies were $\sim 95 \%$ for $\mathrm{MB}$ and $\sim 90 \%$ for RhB after $3 \mathrm{~h}$ and $4 \mathrm{~h}$, respectively. Overall, the novel $\mathrm{Bi}_{2} \mathrm{Se}_{3}$ NPs/PEI material is a promising antibacterial agent and good photocatalyst for bacterial infections and drinking water purification. Finally, the developed $\mathrm{Bi}_{2} \mathrm{Se}_{3}$ NPs/PEI preferentially adsorbed cationic dyes via strong electrostatic interactions. Future expansion of its application to anionic dyes like methyl orange and Congo red, and the possible drop in adsorption efficiencies and the degradation efficiencies for these dyes must be considered.

\section{Conflicts of interest}

There are no conflicts to declare. 


\section{Acknowledgements}

We are grateful for the financial support of the Ministry of Science and Technology, Taiwan (MOST 104-2113-M-007-008MY3 and MOST 104-2923-M-007-002-MY3) and the National Tsing Hua University for this work.

\section{References}

1 Y. Tsai, P. Cheng and T. Pan, J. Agric. Food Chem., 2010, 58, 1207-1212.

2 Y. W. Wang, Y. Y. Fu, L. J. Wu, J. Li, H. H. Yang and G. N. Chen, J. Mater. Chem. B, 2013, 1, 2496-2501.

3 C. J. Jeong, S. M. Sharker, I. In and S. Y. Park, ACS Appl. Mater. Interfaces, 2015, 7, 9469-9478.

4 S. Chen, F. Tang, L. Tang and L. Li, ACS Appl. Mater. Interfaces, 2017, 9, 20895-20903.

5 Y. Jin, J. Deng, J. Yu, C. Yang, M. Tong and Y. Hou, J. Mater. Chem. B, 2015, 3, 3993-4000.

6 X. Liu, G. Yang, L. Zhang, Z. Cheng and X. Zhu, Nanoscale, 2016, 8, 15323-15339.

7 S. Wang, A. Riedinger, H. Li, C. Fu, H. Liu, L. Li, T. Liu, L. Tan, M. J. Barthel, G. Pugliese, F. De Donato, M. S. D'Abbusco, X. Meng, L. Manna, H. Meng and T. Pellegrino, ACS Nano, 2015, 9, 1788-1800.

8 T. J. Ondera and A. T. Hamme, J. Mater. Chem. B, 2014, 2, 7534-7543.

9 A. Gharatape, M. Milani, S. H. Rasta, M. P. Moghaddam, S. A. Kandjani, S. Davaran and R. Salehi, RSC Adv., 2016, 6, 110499-110510.

10 M. C. Wu, A. R. Deokar, J. H. Liao, P. Y. Shih and Y. C. Ling, ACS Nano, 2013, 7, 1281-1290.

11 M. Sinha, G. Gollavelli and Y. C. Ling, RSC Adv., 2016, 6, 63859-63866.

12 C. Korupalli, C. C. Huang, W. C. Lin, W. Y. Pan, P. Y. Lin, W. L. Wan, M. J. Li, Y. Cang and H. W. Sung, Biomaterials, 2017, 116, 1-9.

13 D. R. Rice, H. Gan and B. D. Smith, Photochem. Photobiol. Sci., 2015, 14, 1271-1281.

14 Z. Lim, J. L. Cheng, T. W. Lim, E. G. Teo, J. Wong, S. George and A. Kishen, Aust. Dent. J., 2009, 54, 108-114.

15 B. Z. Ristic, M. M. Milenkovic, I. R. Dakic, B. M. T. Markovic, M. S. Milosavljevic, M. D. Budimir, V. G. Paunovic, M. D. Dramicanin, Z. M. Markovic and V. S. Trajkovic, Biomaterials, 2014, 35, 4428-4435.

16 J. A. R. Herrera, J. Sanabria, F. Machuca, C. F. Dierolf, C. Pulgarin and G. Orellana, J. Sol. Energy Eng., 2007, 129, 135-140.

17 P. Kalluru, R. Vankayala, C. S. Chiang and K. C. Hwang, Angew. Chem., Int. Ed., 2013, 52, 12332-12336.

18 G. Gollavelli and Y. C. Ling, Biomaterials, 2014, 35, 44994507.

19 X. Huang, G. Chen, J. Pan, X. Chen, N. Huang, X. Wang and J. Liu, J. Mater. Chem. B, 2016, 4, 6258-6270.

20 H. Kusic, N. Koprivanac and A. L. Bozic, J. Photochem. Photobiol., A, 2013, 252, 131-144.
21 X. Zhong, Z. Dai, F. Qin, J. Li, H. Yang, Z. Lu, Y. Liang and R. Chen, RSC Adv., 2015, 5, 69312-69318.

22 P. Ju, Y. Wang, Y. Sun and D. Zhang, Dalton Trans., 2016, 45, 4588-4602.

23 A. Salabat and F. Mirhoseini, Photochem. Photobiol. Sci., 2015, 14, 1637-1643.

24 A. Y. Booshehri, S. C. K. Goh, J. Hong, R. Jiang and R. Xu, J. Mater. Chem. A, 2014, 2, 6209-6217.

25 Y. Xu, S. Huang, H. Ji, L. Jing, M. He, H. Xu, Q. Zhang and H. Li, RSC Adv., 2016, 6, 6905-6914.

26 W. P. Qin, D. S. Zhang, D. Zhao, L. L. Wang and K. Z. Zheng, Chem. Commun., 2010, 46, 2304-2306.

27 Y. Tang, W. Di, X. Zhai, R. Yang and W. Qin, ACS Catal., 2013, 3, 405-412.

28 S. D. Yang, L. Yang, Y. X. Zheng, W. J. Zhou, M. Y. Gao, S. Y. Wang, R. J. Zhang and L. Y. Chen, ACS Appl. Mater. Interfaces, 2017, 9, 29295-29301.

29 B. Das, N. S. Das, S. Sarkar, B. K. Chatterjee and K. K. Chattopadhyay, ACS Appl. Mater. Interfaces, 2017, 9, 22788-22798.

30 X. D. Zhang, J. Chen, Y. Min, G. B. Park, X. Shen, S. S. Song, Y. M. Sun, H. Wang, W. Long, J. Xie, K. Gao, L. Zhang, S. Fan, F. Fan and U. Jeong, Adv. Funct. Mater., 2014, 24, 1718-1729.

31 G. Song, C. Liang, X. Yi, Q. Zhao, L. Cheng, K. Yang and Z. Liu, Adv. Mater., 2016, 28, 2716-2723.

32 H. Zhang, C. X. Liu, X. L. Qi, X. Dai, Z. Fang and S. C. Zhang, Nat. Phys., 2009, 5, 438-442.

33 K. A. Gibney, I. Sovadinova, A. I. Lopez, M. Urban, Z. Ridgway, G. A. Caputo and K. Kuroda, Macromol. Biosci., 2012, 12, 1279-1289.

34 J. S. M. Nithya and A. Pandurangan, $R S C$ Adv., 2014, 4, 32031-32046.

35 S. Taranejoo, J. Liu, P. Verma and K. Hourigan, J. Appl. Polym. Sci., 2015, 42096, 1-8.

36 M. Jager, S. Schubert, S. Ochrimenko, D. Fischer and U. S. Schubert, Chem. Soc. Rev., 2012, 41, 4755-4767.

37 C. Dun, C. A. Hewitt, H. Huang, J. Xu, D. S. Montgomery, W. Nie, Q. Jiang and D. L. Carroll, ACS Appl. Mater. Interfaces, 2015, 7, 7054-7059.

38 J. Zhang, Z. Peng, A. Soni, Y. Zhao, Y. Xiong, B. Peng, J. Wang, M. S. Dresselhaus and Q. Xiong, Nano Lett., 2011, 11, 2407-2414.

39 S. Subramanian and D. P. Padiyan, Mater. Chem. Phys., 2008, 107, 392-398.

40 B. F. Luo, D. G. Xu, D. Li, G. L. Wu, M. M. Wu, W. D. Shi and M. Chen, ACS Appl. Mater. Interfaces, 2015, 7, 17061-17069.

41 O. Legrini, E. Oliveros and A. M. Braun, Chem. Rev., 1993, 93, 671-698.

42 L. Liu, J. Liu and D. D. Sun, Catal. Sci. Technol., 2012, 2, 2525-2532.

43 Y. Xu, S. Huang, H. Ji, L. Jing, M. He, H. Xu, Q. Zhang and H. Li, RSC Adv., 2016, 6, 6905-6914.

44 S. G. Kumar and K. S. R. Koteswara Rao, $R S C A d v .$, 2015, 5, 3306-3351.

45 C. Sushma and S. G. Kumar, Inorg. Chem. Front., 2017, 4, 1250-1267. 